\title{
11. Conclusion
}

\section{Jacqueline O'Reilly, Bjørn Hvinden, Mi Ah Schoyen and Christer Hyggen}

\section{INTRODUCTION}

In this final chapter we bring together the policy implications of the extensive empirical research presented in this volume. We set out to examine four key concepts: well-being, scarring, resilience and active agency. These concepts were used to understand how scarring effects, well-being and social resilience were evident in the lives of young people trying to find stable employment.

The overarching aim of this project has been to provide a gendersensitive, comparative understanding of the short- and long-term consequences of early job insecurity. A distinctive feature of the contributions to this volume has been to offer a bottom-up perspective on how young people are able to negotiate and overcome the difficulties created by early job insecurity. In some cases these young people have been able to benefit from various factors that have enabled them to develop 'transformative resilience' in the face of such adversity. In other cases we have evidence of how these negative experiences have deleterious long-term consequences for later life.

The first key issue has been to identify the consequences associated with trajectories that involve a precarious start in the labour market. Second, we have sought to identify the factors that are present when a person ultimately achieves a more stable outcome. Our third objective has been to interpret how these findings can inform policy recommendations for the future. With these aims in mind, we set out in this chapter to present a brief summary of the main findings together with their policy implications. This is intended to complement the analysis conducted in Volume 1 , which pays more attention to the policy process itself, to cross-national differences in youth transition regimes, to recent policy initiatives such as the Youth Guarantee, and to the use of European Social Funds and multi-level forms of governance intended to alleviate the problem of youth unemployment. 
Here we start by examining the evidence of factors affecting young people's well-being in Europe and how these are related to the recent financial crisis. We then go on to look at scarring effects, before examining the scope for young people's agency to negotiate such situations in times of austerity and the factors that are associated with them being able to make stable transitions. We conclude by summing up the empirical evidence that can be used to inform policymakers with regard to the need to reform existing policy instruments in relation, for example, to the role of advice and guidance, which is so important in helping young people navigate their paths through these difficult times. In addition, by drawing on the work presented in Volume 1, we are able to contextualize individual trajectories that might share similarities across countries and also identify cross-national differences and the specificity of some youth transition regimes and institutions that are meant to help young people.

\section{WELL-BEING}

In Part I of this volume Buttler (Chapter 2 this volume) examines young people's well-being using data from the European Social Survey. He argues that self-reported levels of well-being can provide a reliable proxy for individuals' perceptions of the quality of their own lives. Well-being has also become an important goal of international policymaking and a measure of successful societies. Buttler suggests that the relationship between unemployment and subjective well-being is moderated by active and passive labour market policies, together with forms of employment protection legislation. He is interested in understanding how the concept of 'social resilience' affects 'the transformative capacity. . . to create sets of institutions that foster individual welfare and sustainable societal robustness' in relation to future crises (Dingeldey et al., 2015: 13). He makes the point that it is not only the financial security provided by employment that has a significant effect on an individual's well-being, rather - as Jahoda (1982) argued employment provides the opportunity for creativity, a structured day, social status and sociability with co-workers. In our life-course interviews respondents repeatedly said that employment provided an opportunity to connect in a more psychologically sustaining way with others, compared to the isolation and stigma associated with being unemployed. The consequences of unemployment, especially in the long term, can be significant scarring effects that are not only financial or affect skill attainment, rather are also psychological and affect one's sense of well-being, or lack of it.

Buttler's analysis focuses on the relationship between employment and well-being. He found, as he had expected, a stronger relationship between 
employment and well-being in Nordic and German-speaking countries than in the United Kingdom, Mediterranean countries and Central and Eastern Europe. He argues that the employment-well-being relationship is affected by macro characteristics related to GDP per capita and labour market policy expenditure.

Taking a very different approach based on qualitative life-course interviews, Bøhler et al. (Chapter 3 this volume) outline and distinguish between four grand narratives to summarize youth trajectories across all seven EU countries involved in this study. 'Stumbler' narratives represent young people who had a difficult start but managed to overcome the obstacles in their paths. 'Stigmatized' narratives characterize young people who are discriminated against in terms of factors that they cannot change about themselves, such as ethnicity or disability. The third grand narrative covers those young people who attempted to find work at a time of significant social and economic change and are thus named 'Great Crisis' narratives. The examples cited here draw on cases from the recent economic crisis and the difficulties that compound their attempts to access regular employment. The fourth grand narrative discusses those who have had 'Messy Lives'. These young people have chosen alternative ways of living that contravene established societal norms about appropriate trajectories for young people to integrate into adulthood. Because of these conscious choices, many of these young people have encountered difficulties in achieving stability in later life.

This analysis of four grand narratives is based on an analytical framework that draws on the capabilities approach. The authors propose using seven conversion factors to understand how young people end up in one of these four types of trajectories. These go beyond the criteria established by Sen (2009) and include institutional, societal, familial, economic, cultural, political and personal conversion factors. The authors argue that this more fine-grained distinction between conversion factors enables us to understand how young people navigate situations of adversity. They also identify where young people can draw on resources to enable them to convert this adversity into something that is more constructive and supportive in their own trajectories to adulthood.

This chapter provides an indication of themes that are taken up in relation to the kinds of support mechanisms of which young people can avail. On the one hand, where there is a very clearly structured form of institutional support as indicated by the youth transitions regime perspective, these institutions help enormously. On the other hand, regardless of the societal differences, one of the most important aspects is the relationship young people have with their families and wider social networks. In some cases this relationship can be a 'lifesaver' - when the consequences of risky 
choices result in isolation or detachment. However, it sometimes happens that the family acts to pull the young person down, preventing him (or her) from pursuing some of his (or her) dreams and aspirations.

One of the most significant findings of this research has been to identify how both governmental provisions and family relations through different social networks can either act in a positive way to support young people in difficult situations or reinforce their disadvantages. Where social policy is inadequate, young people are highly dependent on social networks, and in many cases these provide enormously supportive resources that allow them to move on from protracted periods of adversity.

\section{SCARRING}

In Part II of this volume we examine the long-term effects of early job insecurity and evidence of scarring. Helbling et al. (Chapter 4 this volume) compare the long-term scarring effects of unemployment across countries and how it has affected those who graduated from upper-secondary school during an economic downturn. They examine trends in the United Kingdom, Germany, Switzerland, Spain and Finland to illustrate differences between youth transition regimes, using the Eurostat Labour Force Survey from 2014. Their contribution is to advance the conceptualization and measurement of long-term unemployment scarring effects in different institutional and economic contexts. Their chapter addresses a theoretical deficit concerning contextual factors that may explain differential patterns and persistency of scarring in different institutional settings.

Helbling et al.'s analysis suggests that unemployment scars are particularly persistent in the United Kingdom and Germany. Short-term scarring effects were most prevalent in Germany and Switzerland, where the relative rates of youth unemployment were lower. On the other hand, scarring effects did not appear at all in Spain and Finland, two countries with amongst the highest rates of youth unemployment. These findings lead the authors to conclude that employers are more critical of job applicants with an experience of unemployment when rates of youth unemployment are relatively low; this conclusion is also supported by Imdorf et al.'s (Chapter 5 in Volume 1) analysis of recruiter data for Switzerland.

Helbling et al. also found that there was a higher risk of young people taking fixed-term jobs in Germany if they came onto the labour market at times of high youth unemployment. However, eight years after starting work they were also more likely to be in permanent positions. There was no evidence from the other countries of an increase in fixed-term employment for young entrants. 
With regard to part-time employment, they found that in Finland and Germany, and to some degree in Spain (all countries with stricter employment protection legislation), there was a higher engagement in involuntary part-time employment within the first few years of graduating from high school. These effects carried on for up to five years after entering employment in Germany and Spain, but only for two years in Finland. Helbling et al. suggest that young people took up these part-time jobs because of a lack of full-time employment. In the United Kingdom and Switzerland, by contrast, youth were not over-represented in involuntary part-time employment.

In a separate analysis Helbling et al. find gender effects of long-term unemployment scarring for women in Finland and Germany, whereas in the United Kingdom these effects are more evident for men. In Spain long-term scarring effects are evident in the over-representation of young women with fixed-term work contracts; in Switzerland it is young men who are more likely to be found in involuntary part-time employment.

The authors conclude that the evidence is difficult to interpret in terms of the effects of different youth transition regimes. The results are quite sensitive to the inclusion or exclusion of specific school-leaver cohorts, suggesting that a longer period of observation and a larger sample size would be necessary to disentangle some of these institutional effects. Additional country-level factors might be required to explain this further - for example, the degree of globalization; or perhaps greater attention needs to be given to the scarring effects of non-standard working arrangements. Nonetheless, one clear piece of evidence from this analysis remains: that looking for work during a recession means that many young people move into fixed-term and involuntary part-time employment as a result of a lack of permanent and full-time jobs (Grotti et al., 2018).

Following up on this theme of scarring and the potential impact of labour market policies in moderating the effects of unemployment for young people, Parsanoglou et al. (Chapter 5 this volume) compare two contrasting countries: Greece and Norway. Here they used the particularly innovative method of a vignette experiment to evaluate employers' discrimination likelihoods towards young people who have had an experience of unemployment. These authors were interested in finding out how prospective employers use information about job candidates who have participated in active labour market measures, also wanting to compare differences in educational attainment, gender and periods of time spent in unemployment. They find that in Norway recruiters have more reservations about hiring somebody who has recently been unemployed, although this was less marked in the mechanics sector. In Greece employers' reservations are less apparent: only in the catering sector was there evidence that employers had a negative view of those who had been unemployed. 
With regard to those who had participated in active labour market measures, employers in Norway more often than employers in Greece viewed these negatively. Employers in the finance sector in both countries were negatively disposed to young people coming from labour market programmes; employers in the Norwegian health sector had the strongest negative feelings towards these young people. Employers who were more positively disposed to young people coming from these programmes were found in the Greek mechanics sector and in catering in Norway.

Overall, the authors found that having participated in one of these labour market programmes was more likely to have a positive effect on finding a job in Greece, whereas in Norway such programmes either had no effect or negative effects on the likelihood of being hired.

With regard to gender differences, the only difference the authors observed was the positive effect of participating in active labour market policies for Greek men; in Norway there was no observed gender difference. Educational attainment also had an effect. In Greece candidates with a higher level of education and who had participated in a programme had a higher likelihood of being hired, especially if they were young men. The effects in Norway were the opposite. Employers viewed a better-educated candidate coming from a labour market programme more negatively, and this was more pronounced for female candidates who had completed tertiary education.

Parsanoglou et al. conclude that in countries like Greece where youth unemployment rates are high, having participated in a labour market programme is perceived in a more positive way by employers than is the case in Norway, where youth unemployment rates are relatively low. They argue that labour market programmes need to be understood in their broader macroeconomic context and institutional framework, which affect both vocational education and training and labour market regulation in general. Their policy recommendations reflect on the fact that national and especially sectorial specificities need to be taken into account when developing such programmes for young unemployed people.

The final chapter in this section on scarring provided by Abebe and Hyggen (Chapter 6 this volume) focuses on a longitudinal study from Norway. These authors are particularly interested in understanding how exposure to early job insecurity and unemployment relates to both individual and family characteristics. The choice to focus on one country allows Abebe and Hyggen to draw on a rich and unique data set that includes a number of personal characteristics, for example in relation to questions around self-esteem and other personality traits, as well as family characteristics and relationships. 
The authors point out that in terms of gender differences young women appear to suffer less from scarring effects than is the case for young men. However, the effects of unemployment on wage scarring were higher for young women than for young men.

In their analysis Abebe and Hyggen find somewhat more prevalent psychosocial problems amongst those who were previously unemployed compared to those who had previously been employed. They also found that the average effect of unemployment scarring was statistically significant. Psychosocial well-being moderates unemployment and wage scarring; low levels of education were associated with deeper scarring effects compared to those with higher levels of education. Parental levels of education did not appear to be associated with unemployment scarring effects, but those whose parents had low levels of education were more likely to experience wage-scarring effects.

In conclusion Abebe and Hyggen argue on the basis of their analysis that periods of youth unemployment leave long-term scars in relation to both future periods of unemployment and wages. They find significant differences in terms of gender, levels of education, the effect of parental education and psychological well-being. These factors moderate the effects of early periods of unemployment on long-term labour market outcomes. The authors argue that the more severe scarring effects on young females in Norway may in part be attributable to gendered occupational segregation in Norwegian labour markets. Young men's higher probability of experiencing unemployment is attributed to the fact they are more likely to work in the less well-protected private sector. In all cases higher levels of education act as a buffer against some of the scarring effects that are attributable to being unemployed.

\section{RESILIENCE}

In Part III of this volume we look at various ways in which young people develop resilience. The chapter by Bussi et al. (Chapter 7 this volume) examines positive trajectories of young people who have confronted adversity and found ways of dealing with difficult situations. This chapter draws on the capabilities approach, comparing the way young people in Norway and the United Kingdom have been able to adjust to difficult transitions.

One of the key issues that Bussi et al. identify has been the changing importance of different factors, for example the significance in Norway of the public employment services (PES) in helping people find work. While older respondents were more likely than younger respondents to cite the 
PES as a significant conversion factor in helping them find employment, younger respondents gave more weight to the role of education, often combined with support from the PES. In the United Kingdom there was less observable difference between the age cohorts, and recourse to the PES was negligible.

Education has become the key conversion factor associated with the ability to get a good job. Education was important for older as well as for younger respondents, especially in the United Kingdom. But it was more likely that the older respondents had availed of this factor as mature students returning to study in the United Kingdom rather than benefitting from it when they were younger.

Social networks and family support as conversion factors that enabled them to find more stable employment were cited more often by respondents from the United Kingdom than by those in Norway. As part of these networks, volunteering was more often mentioned by the UK respondents as a way into a type of work they valued, whereas this pathway was barely referred to in the Norwegian interviews. While these qualitative data cannot claim to be representative, they do provide an insight into how different youth transition regimes affect youth trajectories. While the Norwegian case clearly has a more robust set of institutional arrangements from which young people have benefitted, in the United Kingdom there was greater reliance on informal social networks than on the PES.

The importance of social networks also becomes very apparent when examining young people's decisions to migrate abroad to find work. Recent decades have seen some of the largest migration flows across Europe, and a distinctive characteristic of this development has been the number of mobile young Europeans (O'Reilly et al., 2015, 2017, 2018). Krasteva et al. (Chapter 8 this volume) examine the experiences of three young people from Bulgaria, Norway and the United Kingdom who migrated to find work abroad. They argue this is an example of active agency in relation to institutional and structural conditions (Dingeldey et al., 2015). All three cases indicate that the motivation to migrate came from an individual sense of adventure. The catalysts for their decision to move were related to the economic circumstances in their home countries (even in Norway there was a recession at the time). The UK and Bulgarian migrants also cited the fact that they could earn considerably more money in Germany and Greece, respectively, than they would be able to do if they were to stay at home. The types of employment found in both of these cases were frequently informal, without a proper employment contract and without any social insurance contributions or benefits. Even the Norwegian young woman who worked as an au pair in the United Kingdom found that her situation was subject to the vagaries of the families that employed her. 
Nevertheless, all three young people still felt like they were earning enough (or in the case of the young British man a very comfortable income) to support a lively social life with some of the new friends they had met abroad. In all three cases the interviewees had a very positive appreciation of their experiences, which they believed had allowed them to lead more unconventional lifestyles than if they had remained at home. Their experiences had also increased their range of skills and abilities beyond learning another language. The conversion factors that allowed them to make these moves were often rooted in social networks of friends and acquaintances, even in circumstances when their own families were not supportive of them making these transitions. Although the cases chosen here had a very positive outcome, we also know that for some young people these migratory transitions are associated with exploitation and in the worst cases trafficking and illegality. Krasteva et al. also recognize the need to create safe and secure conditions where young migrant skills are more easily recognized across borders and where national labour regulations are implemented.

Youth trajectories that err on the side of illegality are discussed in the chapter by Ayllón et al. (Chapter 9 this volume), who examine the consequences of early job insecurity and the use of drugs. They provide a comprehensive study drawing on recent quantitative Eurobarometer data for the EU combined with a selection of life-course interviews from Germany, Poland and the United Kingdom. They find an association between an increase in youth joblessness and an increased use and perceived access to drugs (such as cannabis and 'new substances' in the form of powders, pills or herbs).

Ayllón et al. argue that 'critical moments', both at the societal and individual level, together with the role of 'significant others' in the lives of vulnerable young people, can affect their trajectories in both positive and negative ways. For some young people drug use is related to criminal activity as part of creating an alternative lifestyle, contrary to societal norms. Shildrick and MacDonald (2007) suggest that these 'independent careers' can be a product of already being excluded and that they serve to reinforce the sense of detachment from the mainstream. Bøhler et. al. (Chapter 3 this volume) discuss some of these cases as part of the grand narrative of 'Messy Lives'.

While Ayllón et al. recognized that some young people are capable of using recreational drugs and continuing to work or study, they were particularly interested in understanding how the recent soaring levels of youth unemployment might relate to an increase in drug consumption amongst young people. They found both a clear relationship and an increase in consumption. They also found amongst those who admitted to using various types of drugs a perception that access to these had become 
easier. Finally, they found, in relation to the use of ecstasy, that when unemployment increased, more young people believed that using this drug did not harm their health.

The qualitative interviews provide us with a longer-term historical perspective drawing on interviews with older people who were involved with drugs when they were young. The value of weaving together these different sources of data is to illustrate the long-term consequences of taking these paths in early career transitions. Some of the salient characteristics that emerge from these qualitative stories are the effects of growing up in hostile neighbourhoods and critical life moments, and the role of supportive, or unsupportive, family members or 'significant others'. In some cases having being involved with taking and dealing in drugs and other illegal activities meant that these people ended up in the criminal justice system or in prison. Following an unconventional pathway in their youth significantly scarred their later life trajectories. In some cases, however, they had tried to turn their lives around. A range of therapeutic programmes provided by the PES supported these efforts to get their lives back on track, for example in Germany. However, the young person interviewed in this case still attributed his failures to his own behaviour and criminality. In other cases there were more successful outcomes. The people interviewed attributed this to having had the support of a 'significant other' in their life: someone they respected and could rely on, who sometimes was a family member and in other cases was a significant professional that they had come to trust and respect. What these cases clearly illustrate is that taking an unconventional pathway associated with drug use had been catalysed for these young people by a critical moment or tragedy in their personal lives. Once on this pathway they found it very difficult to get out of the downward spiral without the help and support of 'significant others' to motivate them to make a change. The importance of guidance and advice in a formal policy environment is taken up again in the chapter by Lewis and Tolgensbakk (Chapter 10 this volume).

The evidence of the impact of 'significant others' in the lives of the people we have interviewed illustrates the need for supportive advice and guidance to be provided to young people, and especially to those who do not have the benefit of personal contacts to help them. This is a complex and difficult policy to introduce successfully, as discussed in Lewis and Tolgensbakk's chapter. In their comparison of Norway and the United Kingdom they point out how good-quality career education, information, advice and guidance (CEIAG) are crucially important in helping young people find a place in the labour market, especially for those at risk of becoming NEET or dropping out of school early. Drawing on data from the life-course interviews, they capture a range of opinions across the cohorts in each 
country with regard to their experience of having received careers advice and guidance from official authorities. Overall, in both countries there was significant evidence of a general dissatisfaction with the level of engagement and advice people had received from these official bodies. Nevertheless, there were some respondents who recounted that without their personal careers adviser's support they would not have been able to manage various mental health challenges they needed to deal with in their early 20 s.

One of the recommendations coming out of this analysis emphasizes the need for coordinated services between medical staff, social workers and those employed in the job centre. In particular, Lewis and Tolgensbakk argue that benchmarks of good practice in careers advice and guidance require a stable careers advice programme to be embedded in local and regional skills strategies; support from informed advisers who understand the personal needs of young people individually; advisers who understand the relationship between curriculum learning and career options; and advisers who build partnerships with employers, colleges and universities. The Norwegian services anticipate a process of automation and ICT support and communications to enable them to simplify the system of following up users, while the provision of dynamic guidance with enhanced user involvement should be blended together with face-to-face advice.

After reviewing the extent of policy reforms around advice and guidance in both countries Lewis and Tolgensbakk indicate some of the barriers that emerge with regard to effective implementation of CEIAG policies. These include changing political priorities, the challenges of coordination between different sectors and the lack of political engagement to increase funding for guidance services.

Finally, they recognize that while good-quality CEIAG is important, it also matters that work experience, internships and apprenticeship programmes are of a good standard so that the young people undertaking this work feel that they are engaged in a meaningful activity that they value.

\section{CONCLUSION}

Notwithstanding indications of a beginning economic recovery in Europe, youth unemployment rates, NEET rates and non-standard forms of employment among young people are still high in many countries. Early job insecurity has even increased for some groups of young people in Europe. Low-skilled, immigrant or ethnic-minority-background youth are still affected heavily in spite of the policy initiatives adopted at the EU and national levels to improve the situation of young people on the labour market. In most countries young women are in a more vulnerable 
position in relation to the labour market than young men. Furthermore, for many of those who have experienced - or still are affected by - early job insecurity there are likely to be long-term scarring effects in the form of poorer employment prospects. Drawing on the evidence presented here from the NEGOTIATE project, we address the crucial question: How can policies to integrate young people in the labour market be improved?

The evidence presented here indicates that divergences amongst European countries persist. This situation calls for an overall reassessment of early job insecurity in Europe. There is a need to rethink individualistic or narrowly focused approaches in dealing with problems of integration in the labour market and instead to take into account the role of structural constraints that shape contemporary realities of early job insecurity across Europe. We set out to understand how four key concepts - well-being, scarring, resilience and active agency - could help us understand this in relation to scarring effects, well-being and social resilience in the lives of young people facing adversity in trying to find stable employment.

We found that job insecurity and labour market marginalization are a threat to the economic, social and personal situation of young Europeans. High levels of unemployment, joblessness and economic uncertainty affect their objective and subjective well-being. Labour market insecurity is more detrimental for men than for women in terms of predicting future periods of unemployment, but women are more likely to experience wage-scarring effects. Social support, work dissatisfaction, level of education and employment commitment, work contracts and regional unemployment may moderate these effects. But early job insecurity often creates a stigma, engenders welfare dependence and lowers the self-esteem of young people.

Entering the labour market in an economic downturn leads to scarring beyond temporary setbacks with varying effect across educational groups and gender. When designing labour market regulations and active labour market policies, there is a need to focus more on trajectories than on single jobs spells, because the accumulation of insecurity in the labour market over time is essential to explaining why some groups are more at risk of scarring than others.

There is a need to distinguish between different forms of early job insecurity. Work in deskilling jobs, frequent changes of jobs or even participation in active labour market measures can be detrimental to a young worker's professional career. Unemployment measures aimed at a quick labour market reintegration of the young unemployed, without the consideration of job quality, may not help or, worse, may even decrease their employability. This suggests that both 'skill-building first' and 'work-first' strategies may have an ambiguous or even negative impact on the longterm job prospects of young people, depending on the national context. 
The strong and persistent divergences in national levels of youth job insecurity across Europe challenge the European Employment Strategy and European solidarity, for instance leading to an overtaxing of migration as a strategy for coping with poor job prospects in the young person's own country, with uncertain gains for the person's long-term employment prospects. National PES need to assess carefully which measure seems appropriate in the individual case, given the person's prior skills and job experience, as well as the country's current labour market situation.

Despite their more or less common experiences during the Great Recession, none of the countries studied moved towards other transition regimes, nor towards an emerging 'European Transition Regime'. The EU needs to address the unrealized potential for policy learning and exchange of best practice between member states in the context of the European Employment Strategy, as discussed in Volume 1. The EU has good reason to safeguard the progress that has been made and to keep on encouraging member states in several areas (e.g., by completing reforms like the already initiated Youth Guarantee), delivering comparable data to enable monitoring of labour market developments and stricter evaluation of the effectiveness and sustainability of the Youth Guarantee and other instruments.

While continuing to support the Youth Guarantee in the coming financing periods of the European Social Fund, the EU needs to use financial instruments to promote better balances between supply- and demandoriented measures in member states. Both the EU and member states (at different levels of governance) need to recalibrate cash transfers and services supporting young women's and men's active efforts to improve their skills and prospects for finding secure jobs. Public agencies need to coordinate their approaches with those of civil society organizations in enabling young people's own agency and in listening to young people's own views when developing new policies.

The integration of the social partners and other stakeholders in the design and monitoring of youth employment measures, but also in the vocational education and training systems and systems of careers advice and guidance, is crucial to meeting the needs of the economy as well as to safeguarding the quality of work and education, including fair wages.

\section{REFERENCES}

Dingeldey I, Hvinden B, Hyggen C, O'Reilly J and Schoyen MA (2015) Understanding the consequences of early job insecurity and labour market exclusion: The interaction of structural conditions, institutions, active agency and capability. 
NEGOTIATE Working Paper no. 2.1. https://negotiate-research.eu/files/2015/04/ NEGOTIATE-working-paper-no-D2.1-1.pdf (accessed 16 May 2018).

Grotti R, O'Reilly J and Russell H (2018) Where do young people work? In: O'Reilly J, Leschke J, Ortlieb R, Seeleib-Kaiser M and Villa P (eds) Youth Labor in Transition. Inequalities, Mobility, and Policies in Europe. New York: Oxford University Press, Chapter 2.

Jahoda M (1982) Employment and Unemployment: A Social-Psychological Analysis. Cambridge, MA: Cambridge University Press.

O’Reilly J, Eichhorst W, Gábos A, Hadjivassiliou K, Lain D, Leschke J, McGuinness S, Mýtna Kureková L, Nazio T, Ortlieb R, Russell H and Villa P (2015) Five Characteristics of Youth Unemployment in Europe: Flexibility, Education, Migration, Family Legacies, and EU Policy. SAGE Open 5(1): 1-19. DOI: $10.1177 / 2158244015574962$.

O'Reilly J, Leschke J, Ortlieb R, Seeleib-Kaiser M and Villa P (eds) (2018) Youth Labour in Transition: Inequalities, Mobility, and Policies in Europe. New York: Oxford University Press.

O'Reilly J, Moyart C, Nazio T and Smith M (eds) (2017) Youth Employment: STYLE Handbook. Brighton, UK: CROME, University of Brighton. Ebook: http://style-handbook.eu/ (accessed 31 May 2018).

Sen, A (2009) The Idea of Justice. Cambridge, MA: The Belknap Press of Harvard University Press.

Shildrick, T. and MacDonald, R. (2007) Biographies of exclusion: poor work and poor transitions. International Journal of Lifelong Education 26: 589-604. https://doi.org/10.1080/02601370701559672. 
